\title{
Determination of vancomycin and methicillin resistance in clinical isolates of Staphylococcus aureus in hospitals of Ilam city
}

\author{
Arman Rostamzad $^{1 *}$, Nabi Rostamneia ${ }^{1}$, Fazel Pourahmad ${ }^{2}$, Morteza Shamsi $^{3}$
}

1. Department of Biology, Faculty of Sciences, Ilam University, Ilam, Iran

2. School of Veterinary Medicine, Ilam University, Ilam, Iran

3. Department of Parasitology, Faculty of Medicine, Ilam University of Medical Sciences, Ilam, Iran

*Corresponding author:Tel: +98 9188412905 Fax: +98 8432227022

Address: Department of Biology, Faculty of Sciences, Ilam university, Ilam,Iran.

E-mail: arostamzad381@yahoo.com

Received; 2015/11/9 revised; 2015/12/21 accepted; 2016/1/21

\section{Abstract}

Introduction: In this study, using the phenotypic and genotypic methods, oxacillin susceptibility in Staphylococcus aureus (S. aureus) strains isolated from patients at two government hospitals in Ilam, Iran was tested.

Materials and methods: Out of 200 S. aureus isolates from different human clinical specimens consisting of blood (31\%), wound (20\%), urine (21\%), catheters $(7 \%)$, sputum (12\%), others $(9 \%)$ were collected. The methicillin resistant $S$. aureus isolates were investigated using disk diffusion methods and oxacillin $(1 \mu \mathrm{g})$ and cefoxitin $(30 \mu \mathrm{g})$, on MuellerHinton agar were used, and MecA and vanA genes were detected by PCR. In addition, the isolates were tested for their antibiogram profiles.

Results: Among $200 \mathrm{~S}$. aureus strains included in this study, 35.96\% were MRSA. The percentage of resistance by disk diffusion method was as below: penicillin $85.96 \%$, vancomycin $0 \%$, ampicillin $87.71 \%$, gentamicin $48.25 \%$ erythromycin $54.25 \%$, clindamycin $32.45 \%$, amikacin $21.05 \%$, ciprofloxacin $42.10 \%$, tetracycline $51.75 \%$ and co-trimoxazole 42.10\%. Phenotyping method by disk diffusion method using oxacillin and cefoxitin for detecting of MRSA showed sensitivity and specificity of about $33.33 \%$ and $35.96 \%$, respectively. Presence of MecA and vanA genes in MRSA isolates by PCR were $35.96 \%$ and $0 \%$, respectively. The oxacillin and cefoxitin disk diffusion methods showed $92.68 \%$ and $100 \%$ sensitivity, respectively, and $98.8 \%$ specificity.

Conclusion: Our finding showed that, the cefoxitin disk diffusion method is better in compared to the oxacillin disk diffusion similar to results from detecting of $\mathrm{MecA}$ gene in PCR as a golden test.

Keywords: Staphylococcus aureus, MecA, Methicillin, Vancomycin

\section{Introduction}

Staphylococcus aureus frequently is a member of the normal skin flora and nasal cavity often causes abscesses, infections of wound, skin, soft tissue, osteomyelitis, endocarditis, pneumonia etc. It may also cause staphylococcal scalded skin syndrome, a severe disease in infants or the toxic shock syndrome (1). The previous data provided that the high virulence potential of MRSA is associated with genes like capsule, clumping factor, toxins and some genes as vancomycin and methicillin resistance (2). An important result rises from previous researches suggest these that characterization of MRSA isolates requires diagnosis of mec element, which carries methicillin resistance determinant $\mathrm{Mec} \mathrm{A}$ (3). Staphylococcus aureus is a inherit pathogen causes a variety range of disease, such as wound infections, pneumonia, 
septicemia, etc., with beta-lactam antibiotics being the drugs of choice for therapy (4).Detection of MRSA strains is important for the treatment of infections caused by these strains(5). The aim of this study was to determination of Vancomycin and Methicillin Resistance in Clinical Isolates of Staphylococcus aureus in Ilam Hospitals using disc diffusion method and detecting of $M e c A$ gene by PCR.

\section{Materials and methods}

Samples collection: A total of 200 nonduplicated S.aureus isolates used in this study were randomly collected from inpatient and outpatient of tow government hospitals from Ilam city in Iran, during September 2012 to October 2013.The specimens of clinical consisted blood (31\%), wound (20\%), urine (21\%), catheters $(7 \%)$, sputum $(12 \%)$, others $(9 \%)$. Then all S.aureus isolates were stored frozen at $-80 \mathrm{C}$ in Skim Milk broth, containing $10 \%$ glycerol.

Laboratory methods: Specimens were screened by Gram's stain and were cultured on $10 \%$ sheep blood agar and MacConkey's agar. All isolates were identified by catalase production, haemolysis on blood agar, oxidative-fermentative test, and production of bound and free coagulase, manitol fermentation and 7.5 percent $\mathrm{NaCl}$ tolerance and heat labile DNase. Tube coagulase production is considered "gold standard" for identification of S.aureus (6). Antimicrobial Susceptibility Test: Disk diffusion test of Penicillin (10 U), vancomycin $(30 \mu \mathrm{g})$, Ampicillin $(10 \mu \mathrm{g})$, Gentamicin $(10 \mu \mathrm{g})$, Erythromycin $(15 \mu \mathrm{g})$, Clindamycin $(2 \mu \mathrm{g})$, Amikacin $(30 \mu \mathrm{g})$, ciprofloxacin $(5 \mu \mathrm{g})$, Tetracycline $(30 \mu \mathrm{g})$, Co-trimoxazole $(25 \mu \mathrm{g})$ (Mast, Merseyside, United Kingdom), was carried out using Kirby-Bauer Method according to CLSI guidelines 2011. The inoculums (turbidity equivalent to that of a 0.5 McFarland Standard) of the S.aureus clinical isolates were cultured on Mueller-Hinton agar plates and after $24 \mathrm{~h}$ incubation at $37 \mathrm{C}$, the Zone diameters were measured as CLSI guideline (7). The minimal inhibitory concentration (MIC) of oxacillin, cefoxitin, and vancomycin was determined only for MRSA isolates by agar dilution method. Briefly, gradient plates of Mueller-Hinton agar (Hi Media India) were prepared with vancomycin, cefoxitin and oxacillin (0.5$256 \mathrm{mg} / \mathrm{l}$, Sigma- Aldrich). 0.5 McFarland equivalent inoculum prepared using 18-24 $\mathrm{h}$ old culture was spotted on to gradient plates and incubated at $37^{\circ} \mathrm{C}$ for $24 \mathrm{~h}$ before assessing the visible growth as recommended by the National Committee for Clinical Laboratory Standards (8). MSSA (ATCC 6538) and MRSA (ATCC 33591) were included as control strains for disk diffusion (2).

Detection of methicillin resistant isolates: Detection and confirmation of methicillin resistant S.aureus isolates was carried out using disk diffusion method and following disks were used: oxacillin $(1 \mu \mathrm{g})$, and cefoxitin $(30 \mu \mathrm{g})$. The plates were incubated for $24 \mathrm{~h}$ at $37{ }^{\circ} \mathrm{C}$ and antimicrobial activity was evaluated by determining the diameter of the inhibition zone as recommended by the CLSI $(9,10)$. Then results were compared with $M e c A$ gene detecting using PCR.

DNA Extraction: Total genomic DNA was extracted using phenol-chloroform isoamyl alcohol (Merck, Darmstadt, Germany). The specimens were pelleted followed by adding $250 \mu \mathrm{L}$ buffer I and buffer II containing RNase (CinnaGen, Tehran, Iran). A $550 \mu \mathrm{L}$ volume of phenol was added to the aliquots before being centrifuged at $10000 \mathrm{~g}$ for $5 \mathrm{~min}$, the supernatant clear phase was then collected into new eppendorf tube and the latter stages was repeated twice in order to wash cell derbies. A 0.1 volume of sodium acetate $0.1 \mathrm{M}$ was then added to the tubes, washed twice using ethanol 100 and $80 \%$, respectively. The tubes were then centrifuged at $12000 \mathrm{~g}$ for $15 \mathrm{~min}$. The pellet was finally dried and re-suspended in $30 \mu \mathrm{L}$ Tris-EDTA buffer and used as template in PCR screening (11). 
PCR- based detection of Vancomycin and Methicillin resistant genes in isolates: In all coagulase positive isolates the resistance genes were detected by PCR. They included genes for methicillin resistance, and vancomycin resistance (12). The PCR primers used to detect resistance genes are listed in Table 1(13, 14). The PCR mixture was prepared in a final volume of $25 \mathrm{ml}$. The amplification mixture consisted of $2.5 \mathrm{ml}$ template DNA, $2 \mathrm{ml}$ primers, $2 \mathrm{ml}$ of a 10-fold concentrate PCR buffer, $2 \mathrm{ml}$ dNTP, $0.5 \mathrm{mM} \mathrm{MgCl} 2,15 \mathrm{ml}$ D.W. and $1 \mathrm{U}$ of Taq DNA polymerase (CinnaGen, Tehran, Iran). A thermocycler (Master cycler gradient; Eppendorf, Hamburg, Germany) was programmed for genes with the following parameters:

Detection of $M e c A$ : Initial denaturation at $94^{\circ} \mathrm{C}$ for 3 min was followed by 30 cycles of amplification with $94^{\circ} \mathrm{C}$ for $30 \mathrm{~s}$, annealing at $55^{\circ} \mathrm{C}$ for $30 \mathrm{~s}$, and extension at $72^{\circ} \mathrm{C}$ for $30 \mathrm{~s}$ (except for the final cycle, which had an extension step of $4 \mathrm{~min}$ ). The PCR products were submitted to electrophoresis on 1.5\% agarose gel (MBI Fermentas) containing $0.4 \mathrm{ml} / \mathrm{ml}$ of ethidium bromide and visualized by using UV trans illumination, and photographed (BioDoc- Analyse; Biometra, Goettingen, Germany).
Detection of VanA: Initial denaturation step of 2 min at $94^{\circ} \mathrm{C} ; 30$ cycles of $15 \mathrm{~s}$ at $94^{\circ} \mathrm{C}, 30 \mathrm{~s}$ at $55^{\circ} \mathrm{C}$, and $30 \mathrm{~s}$ at $72^{\circ} \mathrm{C}$; and a final elongation at $72^{\circ} \mathrm{C}$ for $7 \mathrm{~min}$.

\section{Statistical Analysis}

All data analyses of data was carried out using SPSS software version 11.5 for Windows. By using the w2-test and Fisher's exact test, P-Values $<0.05$ were considered statistically significant.

\section{Results}

Diagnosis of isolates using microbiological methods: Out of 200 isolates of Staphylococci collected. The results showed 114 (57\%) were coagulase positive and 86 (43\%) were coagulase negative staphylococcus aureus (CNSA).

Antibiogram profile of isolates: Tables 1 and 2 show the results of antibiotic resistance testing of the MRSA and CNSA isolates to 10 antibiotics studied. The patterns of MICs of oxacillin, cefoxitin, and vancomycin on the MRSA isolates were determined with concentrations varying from $4 \mu \mathrm{g} / \mathrm{ml}$ for vancomycin and 64 to $128 \mu \mathrm{g} / \mathrm{ml}$ for oxacillin and $32 \mu \mathrm{g} / \mathrm{ml}$ for cefoxitin.

Table 1. The primer sequencing for detection of $v a n A$ and $M e c A$ genes.

\begin{tabular}{lcc}
\hline Primer & Primer sequence & Size of product (bp) \\
\hline$M e c A$ forward & AAAATCGATGGTAAAGGTTGGC & 532 \\
vanA forward & AGTTCTGCAGTACCGGATTTGC & 1032 \\
vanA reverse & CATGAATAGAATAAAAGTTGCTGCAATA & \\
\hline
\end{tabular}

Table 2. Antibiotic resistant pattern of MRSA isolates.

\begin{tabular}{lcccccccccc}
\hline Antibiotic & Pen & Van & Amp & Gn & E & Da & Ak & Cip & Te & Ts \\
\hline Number of MRSA & 98 & 0 & 100 & 55 & 62 & 37 & 24 & 48 & 59 & 48 \\
Percentage (\%) & 85.96 & 0 & 87.71 & 48.25 & 54.38 & 32.45 & 21.05 & 42.10 & 51.75 & 42.10 \\
\hline Pen= Penicillin, Van= Vancomycin, Amp= Ampicillin, Gn= Gentamicin= Erythromycin, Da=Clindamycin, Ak= \\
Amikacin, Cip= Ciprofloxacin, Te= Tetracycline, Ts= Co-trimoxazole.
\end{tabular}

Table 3. Antibiotic resistant pattern of CNSA isolates.

\begin{tabular}{lcccccccccc}
\hline Antibiotic & Pen & Van & Amp & Gn & E & Da & Ak & Cip & Te & Ts \\
\hline Number of CNSA & 86 & 0 & 86 & 64 & 68 & 46 & 31 & 40 & 66 & 54 \\
Percentage (\%) & 100 & 0 & 100 & 74.41 & 79.06 & 53.48 & 36.04 & 46.51 & 76.74 & 62.79 \\
\hline
\end{tabular}

Pen= Penicillin, Van= Vancomycin, Amp= Ampicillin, Gn= Gentamicin, E= Erythromycin, Da=Clindamycin, $\mathrm{Ak}=$ Amikacin, $\mathrm{Cip}=$ Ciprofloxacin, $\mathrm{Te}=$ Tetracycline, $\mathrm{Ts}=\mathrm{Co}$-trimoxazole. 
Detection of methicillin resistant isolates: Out of $114(57 \%)$ coagulase positive staphylococci 41 isolates $(35.96 \%)$ were resistant to cefoxitin and 38 isolates $(33.33 \%)$ were resistant to oxacillin, using disc diffusion method.
Detection of $M e c A$ and $\operatorname{VanA}$ genes by PCR: PCR revealed the presence of the $M e c A$ gene in 41 isolates $35.96 \%$, (Figure $1)$, and all isolates were negative for presence of vanA gene (data not shown).

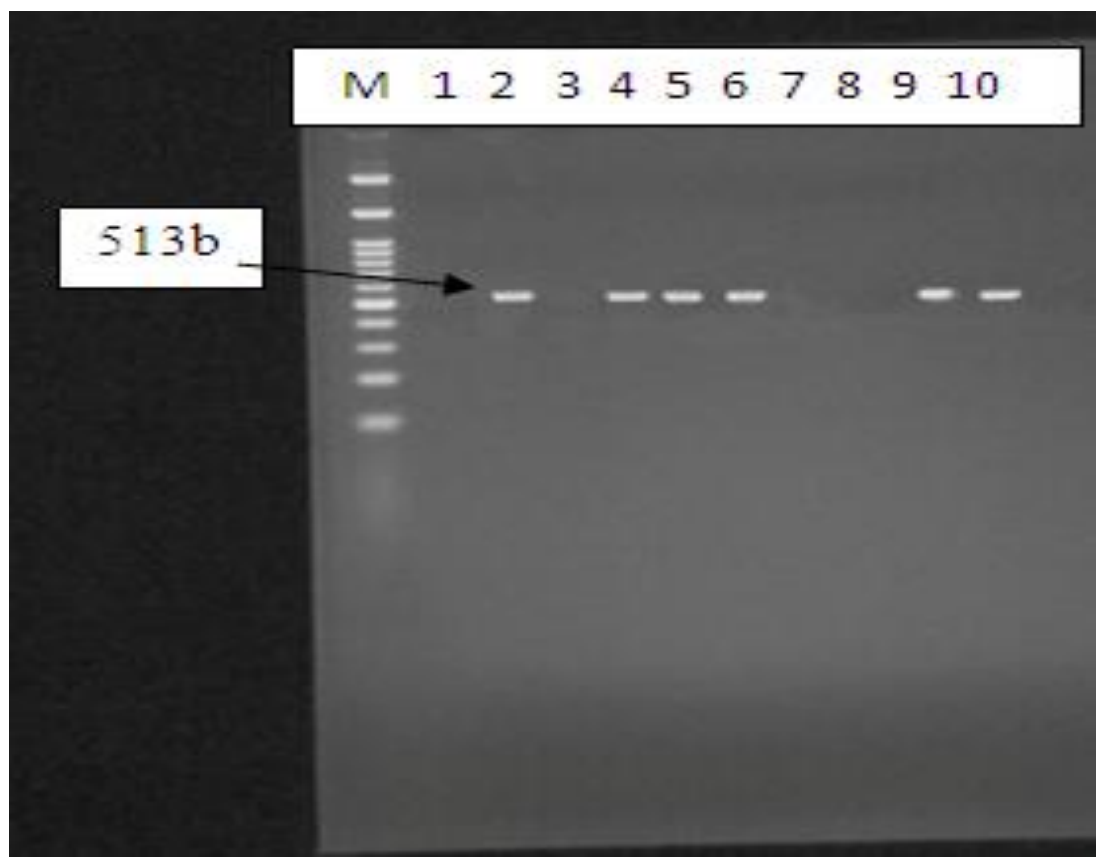

Figure 1. Agarose gel electrophoresis for the detection of the mecA gene (513 bp) in Staphylococcus aureus strains by PCR. Lanes 4, 5, 6, 9, 10: positive strains; lanes 3, 7 and 8: negative strains; lane 2: positive control; lane 1: negative control; lane M: molecular weight marker (100 bp).

\section{Discussion}

Methicillin-resistant S.aureus produces a low affinity penicillin-binding protein (PBP 2a) in addition to usual PBP (15). The structural genes of this PBP (MecA) are present in resistant strains but not in susceptible ones (15). Two mechanisms of resistance described: inactivation of oxacillin and the other is modified resistance, called MOD-SA, due to the production of modified intrinsic PBPs with affinity for altered oxacillin (10). In the present study, 200 S.aureus strains were collected from in-patient and outpatient of two government hospitals from Ilam city in Iran and tested for MRSA. Our finding showed that, the percentage of MRSA isolated from all patients was only $35.9 \%$. Similar results have been reported by
Mohajeri et al, in Kermanshah, western of Iran, with a percentage of MRSA of $36 \%$ (16). Our result also is in agreement to data conducted from Salimnia and Brown among staphylococcus isolates in outpatient and inpatient in Detroit Medical Center (DMC) and from Outreach specimens (17), and Malathi et al. in 2009 with percentage of $36.4 \%$ MRSA isolated from patient (6). Furthermore, the prevalence of MRSA observed here was lower than other reports in Iran and other countries. In a study, conducted by Japoni et al., 2004, in the Nemazi hospital Shiraz, Iran the rate of MRSA $56 \%$ was reported (18) and also the prevalence of MRSA infection of $75 \%$ was reported by Izadi et al., in Tehran, Iran (19). In the United 
States, a prevalence of MRSA infection of $47 \%$ was reported in a hospital in Texas in 2003 (20). In our study, phenotypic tests such as the oxacillin disk diffusion method and cefoxitin disc diffusion method were compared with a genotypic method ( $\mathrm{MecA}$ gene detection by PCR). The cefoxitin disk diffusion method presented 100\% sensitivity and was superior to the oxacillin disk diffusion method (93.18\% sensitivity) in terms of the detection of oxacillinresistant S.aureus using PCR method for detecting of MecA gene. Our data is in agreement to results reported by Velasco et al (21). They reported that, the cefoxitin disk diffusion method, showed 100\% sensitivity and $98 \%$ specificity. Skov et al reported a result, with a sensitivity of about

\section{References}

1. Klein E, Smith DL, Laxminarayan R. Hospitalizations and deaths caused by methicillin-resistant Staphylococcus aureus, United States, 1999-2005. Emerg Infect Dis. 2007; 13(12): 18406.

2. Duarte CO, Hermínia DL. Multiplex PCR strategy for rapid identification of structural types and variants of the mec element in methicillin-resistant. Antimicrob. Agents Chemother. 2002; 46(7): 2155-61.

3. Oliveira DC, Tomasz A, de Lencastre $\mathrm{H}$. Secrets of success of a human pathogen: molecular evolution of pandemic clones of methicillin resistant Staphylococcus aureus. Lancet Infect. Dis. 2002; 2(8): 180-9.

4. Andrea JG, Eva Leitner, Gerhard M, Egon M, Harald HK. Detection of methicillin-resistant Staphylococcus aureus and simultaneous confirmation by automated nucleic acid extraction and real-time PCR. J Clin Microbiol. 2002; 40(7): 2392-7.

5. Alsaimary IEA. Antibiogram and multidrug resistance patterns of Staphylococcus aureus (MDRSA)
$100 \%$ and specificity of $99 \%$ for cefoxitin disk method (22). Cauwelier et al. reported $100 \%$ sensitivity and $99 \%$ specificity, for cefoxitin disk diffusion method whereas sensitivity fell to $91.7 \%$ in the oxacillin disk diffusion test (23). According to our data, compared to the gold standard (MecA gene detection by PCR), the disk diffusion method with $30 \mu \mathrm{g}$ cefoxitin is preferable to the $1 \mu \mathrm{g}$ oxacillin disk diffusion method for the detection of MRSA.

\section{Acknowledgment}

This study was supported by University of Ilam. Iran. Authors are thankful to the Head of the Department of Biology Research Center, Ilam University, Ilam, Iran.

associated with post-operative wound infections in Basrah - Iraq. Med Pract Rev. 2011; 2(6): 66-72.

6. Malathi J, Sowmiya M, Margarita S, Madhavan HN, K. Lily TK. Application of PCR based - RFLP for species identification of ocular isolates of methicillin resistant staphylococci (MRS). Ind J Med Res. 2009; 130(4): 78-84 .

7. CLSI. Performance standards for antimicrobial disc susceptibility tests; approved standard. Document M02A11.10 ${ }^{\text {th }}$ ed. 2011. CLSI.

8. Saeidi S, Ghamgosha M, Taheri RA, Shiri Y, Solouki M, Hassanpour K, et al. Phenotypic and genotypic detection of extended-spectrum $\beta$-lactamase (ESBL) producing Escherichia coli isolated from urinary tract infections in Zabol, Iran. J Coast Life Med. 2014; 2(9), 732-7.

9. Derek FGB. Detection of methicillin/oxacillin resistant in staphylococci. J Antimicrob Chemother. 2001; 48(1): 65-70.

10. Pereira VC, Martins A, de Souza Rugolo LM, de Lourdes R, de Souza da 
Cunha M. Detection of oxacillin resistance in Staphylococcus aureus isolated from the neonatal and pediatric units of a Brazilian teaching hospital. Clin Med Pediatr. 2009; 3(4): 23-31.

11. Shirzadi M, Rostamzad A. Prevalence, antibiotic susceptibility profiles and molecular methods for diagnosis of campylobacter species causing children gastrointestinal in Bahonar hospital in Karaj. World J Pharma Pharm Sci. 2015; 4(5): 260-8.

12. Farhadian A, Behzadian NQ, Najar Peerayeh S, Rahbar M, Vaziri F. Determination of vancomycin and methicillin resistance in clinical isolates of Staphylococcus aureus in Iranian hospitals. Br Microb Res J. 2014; 4(4): 454-61.

13. Cekoveska Z, Panoveski N, Petroveska M. Methicillin- resistant staphylococcus aureus: comparison of susceptibility test methods with $\mathrm{MecA}$ gene analysis for determining oxacillin (methicillin) resistance in our clinical isolates. Bratisl Lik Listy. 2005; 106(4): 163-7.

14. Saha B, Singh AK, Ghosh A, Bal M. Identification and characterization of a vancomycin resistant Staphylococcus aureus isolated from Kolkata (South Asia). J Med Microbiol. 2008; 57(1): 72-9.

15. Utsui Y, Yokota T. Role of an altered pencillin binding protein in methcillin and cephem resistant Staphylococcus aureus. Antimicrob Agents Chemother.1985; 28(3): 397-403.

16. Mohajeri P, Izadi B, Rezaei M, Farahani A. [Frequency distribution of hospital-acquired MRSA nasal carriage among hospitalized patients in west of Iran.] Jundishapur J Microbiol. 2013; 6(6): 1-11.(Persian)
17. Salimnia H, Brown WJ. Detection of oxacillin resistance in Staphylococcus aureus: comparison of phoenix oxacillin and cefoxitin MICs, MicroScan oxacillin MIC, oxacillin and cefoxitin disk diffusion, and MecA gene detection. Antimicrob Agents Chemother. 2005; 32 (3): 1-4.

18. Japoni A, Alborzi A, Rasouli M, Pourabbas B. Modified DNA extraction for rapid PCR detection of methicillinresistant staphylococci. Iran Biomed. J. 2004; 8 (3): 161-5.

19. Izadi M, Zamani MM, Mousavi SA, Mostafa Sadat SM, Siami Z, Vais Ahmadi N, et al. Is vancomycine still a choice for chronic osteomyelitis empirical therapy in Iran? Iran Red Cres Med J. 2012;10(2): 1-5.

20. Fernandes CJ, Fernandes LA, Collingnon P. Cefoxitin resistance as a surrogate marker for the detection of methicillin-resistant Staphylococcus aureus. J Antimicrob Chemother. 2005; 55(1): 506-10.

21. Velasco D, del Mar Tomas M, Cartelle M, Beceiro A, Perez A, Molina F, et al. Evaluation of different methods for detecting methicillin (oxacillin) resistance in Staphylococcus aureus. J Antimicrobiol Chemother. 2005; 55(1): 379-82.

22. Skov R, Smyth R, Larsen AR, FrimodtMoller N, Kahlmeter G. Evaluation of cefoxitin 5 and $10 \mu \mathrm{g}$ disks for the detection of methicillin resistance in staphylococci. J Antimicrobiol Chemother. 2005; 55(1): 157-61.

23. Cauwelier B, Gordts B, Descheemaecker P, Van Landuyt $\mathrm{H}$. Evaluation of a disk diffusion method with cefoxitin $(30 \mu \mathrm{g})$ for detection of methicillin resistant Staphylococcus aureus. Eu J Clin Microbiol Infect Dis. 2004; 23(5): 389-92. 